\title{
DISASTER MANAGEMENT AND HUMANITARIAN LOGISTICS - A SOUTH AFRICAN PERSPECTIVE
}

\author{
WILNA L. BEAN* \\ NADIA M. VILJOEN \\ HANS W. ITTMANN \\ ELZA KEKANA \\ wbean@csir.co.za \\ CSIR Built Environment
}

\begin{abstract}
Disasters are becoming an unavoidable part of everyday life throughout the world, including South Africa. Even though South Africa is not a country affected by large-scale disasters such as earthquakes, the impact of disasters in South Africa is aggravated significantly by the vulnerability of people living in informal settlements. Humanitarian logistics, as a 'new' sub-field in the supply chain management context, has developed significantly recently to assist in disaster situations. This paper provides an overview of the South African humanitarian logistics context. Even though humanitarian logistics plays a critical role in the aftermath of disasters, it extends far beyond events that can typically be classified as 'disasters'. Therefore the implication of the South African humanitarian logistics context on future research and collaboration opportunities in South African humanitarian logistics is also discussed. Finally, two recent case studies in the South African humanitarian logistics environment are discussed.
\end{abstract}

\section{INTRODUCTION}

Disasters have become an unavoidable part of everyday life. Within the first three months of 2010 the world witnessed three major earthquakes:

- Haiti, 12 January 2010: $7 \mathrm{M}_{\mathrm{w}}$

- Chile, 27 February 2010: 8.8 $\mathrm{M}_{\mathrm{w}}$ and 11 March 2010: 6.9 $\mathrm{M}_{\mathrm{w}}$

- Indonesia, 14 March 2010: 6.4-7.0 Mw.

Though the impacts of the Chilean and Indonesian quakes pale in comparison to the catastrophic loss of life and damage of the Haitian quake, they serve as continuous reminders of mankind's vulnerability in the face of disasters.

The term 'disaster' covers a broad spectrum of low-probability, high-consequence events that severely affect human life and damage infrastructure. The schema in Figure 1 is commonly used to classify disastrous events. 


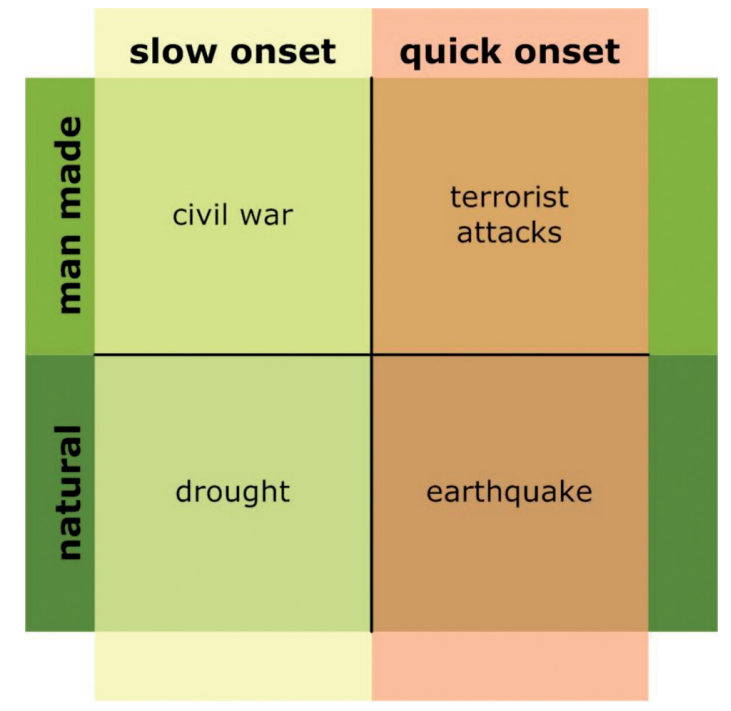

Figure 1: Schema for classification of disastrous events (Adapted from Viljoen, 2010:38)

South Africa is not recognised as a country affected by the large-scale, widely publicised disasters prevalent in other parts of the world. However, even though the 'smaller-scale' disasters occurring in South Africa may be regarded as minor or negligible, the reality is that the impact of a seemingly negligible disaster is exacerbated significantly by the living conditions and subsequent vulnerability of people who are poverty-stricken and/or living in informal settlements.

This paper endeavours to provide an overview of the South African disaster management and humanitarian logistics context. Any country that is affected by disasters requires proper disaster management and an overview is provided of what is being done in South Africa in this regard. All the various role-players are highlighted and the critical role of humanitarian logistics in the aftermath of disasters and in disaster management is described. In addition, it is asserted that humanitarian logistics extends far beyond events that can strictly be classified as 'disasters' to include any form of logistics that aims to relieve human suffering. This paper, therefore, also identifies various research questions and collaboration opportunities in the area of South African humanitarian logistics. Finally, an overview is provided of two South African humanitarian logistics case studies that attempt to answer some of the research questions raised.

\section{SOUTH AFRICAN DISASTER MANAGEMENT AND HUMANITARIAN LOGISTICS}

Internationally, the topic of disaster management has become a great priority to governments, the military, relief organisations and even the private sector. Mitigation, preparedness, response and recovery are the four primary phases in what is considered to be the disaster 
management life cycle. Mitigation and preparedness are pre-disaster phases. While mitigation aims to reduce the likelihood of a disastrous occurrence or to reduce the impact thereof (Altay \& Green, 2006:480), preparedness is the readiness of a country or organisation to effectively reduce the negative impacts through timely provision of aid and services (Perry \& Lindell, 2003:338). The response phase is executed during or directly after a disaster and includes all aid and service provision activities required to eradicate imminent danger to victims. Lastly, recovery is a post-disaster phase during which the affected area and people are restored to a state of normalcy (Altay \& Green, 2006:480). Viljoen (2010:39-40) provides examples of each of these phases and Beamon (2004:2) illustrates the intensity of aid required during the disaster management life cycle.

\section{Role-players and stakeholders in South African disaster management}

The playing field in South African disaster management is much the same as in the rest of the world. Government organisations, the military, police, relief organisations, not-forprofit organisations, research institutions, private sector organisations, the public and, most importantly, disaster victims all constitute the stakeholders in this arena. It is important to distinguish between those who help (termed role-players in this paper) and those who are helped (victims). Role-players are often involved during more than one disaster management phase and fulfil more than one role. Figure 2 depicts how groups of role-players are involved in various activities on different levels of the Strategic-Tactical-Operational continuum. Executing the activities on the Operational level requires much more manpower than executing the activities on the Tactical level. Similarly, the Tactical level requires more manpower than the Strategic level. This is reflected by the triangular shape of the diagram in Figure 2.

Though the South African stakeholder network is very similar to that found in the rest of the world, there are unique characteristics of South African society that directly influence disaster management activities. Community awareness and sensitivity in South Africa (as in many other African countries) are often deciding factors in the outcome of disaster management activities. Many 'outsider' relief initiatives have been hindered by underestimating the influence of community elders, peer pressure, superstitions, and religious and political convictions. On the other hand, when role-players have proactively engaged communities with respect, the positive response has produced great synergies. It should be noted, however, that South Africa is a melting pot of cultures - each with its own perception of community. There is, thus, another dimension of complexity that presents the need, not only for proactive engagement, but for flexible engagement - depending on the stakeholders involved.

The essential role of media - both traditional reporting and emergent social media - to create awareness cannot be disputed. Van Wassenhove (2006:477) describes a 'love-hate' relationship between humanitarians and traditional media reporters. The obvious function of traditional reporting is to: 


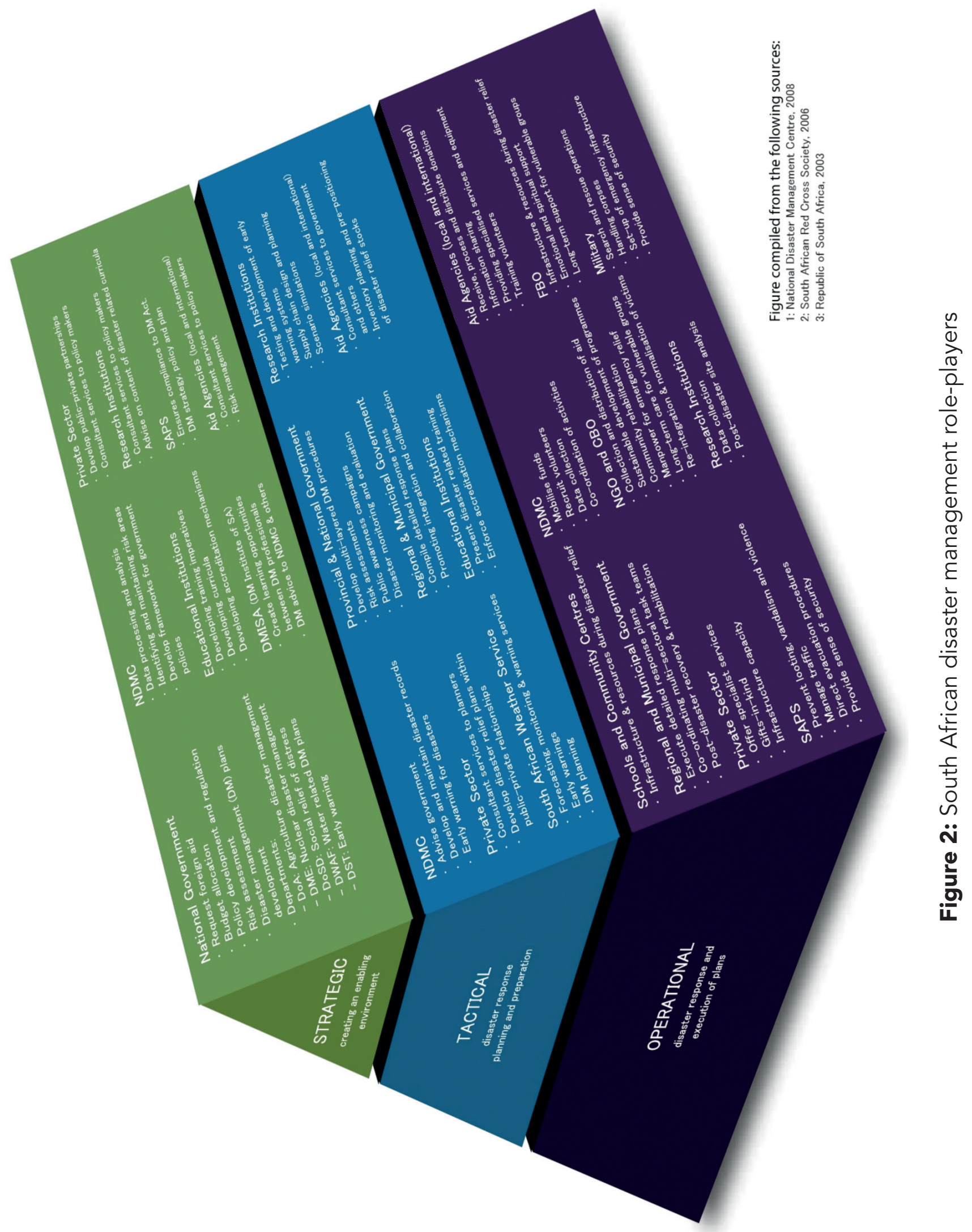


- create awareness and educate the public regarding disasters

- communicate early disaster warnings

- provide information regarding disaster responses and evacuation plans

- disseminate timely and factual information and forecasts

- facilitate communication between role-players and victims.

However, reporters have been blamed for being unbalanced in their reporting. Humanitarians maintain that reporters focus more on what is sensational instead of essential, while reporters cite the need to report on what is urgent and influential.

Social media is an emergent technology receiving much attention from marketing and public relations spheres. These social networks can create or cripple brand reputation by virtual word-of-mouth. Similarly, these pervasive networks have shown their influence in the Haitian earthquake and, more recently, the Moscow bombings (29 March 2010). First-hand reports via social media are expected to be most valuable during initial damage assessment and the critical response period prior to a disaster. Mobile technology has also played a role in search-and-rescue operations during recent disasters. Although social media offer a breakthrough in communication of timely information, the accuracy and verifiability of information is questionable. Currently, humanitarians recognise the potential value of social media while keeping in mind its pitfalls (Georgia Institute of Technology, 2010).

\section{South African humanitarian logistics}

The term 'humanitarian logistics' refers to the management of the disaster relief supply chain and is defined by Thomas and Kopczak (2005:2) as:

the process of planning, implementing and controlling the efficient, cost effective flow and storage of goods and materials as well as related information from the point of origin to the point of consumption for the purpose of alleviating the suffering of vulnerable people. The function includes a range of activities, including preparedness, planning, procurement, transport, warehousing, tracking and tracing, customs and clearance.

Kovàcs and Spens (2007:99) assert that humanitarian logistics is a primary constituent of disaster management as it accounts for approximately $80 \%$ of all disaster relief activities. Tomasini and Van Wassenhove (2009b:2-4) support this assertion by arguing that supply chain management is the key factor for overall effectiveness of the humanitarian response.

The three defining characteristics of humanitarian logistics are identified by Van Wassenhove (2006:478). First, humanity prescribes that a person will be assisted, regardless of the physical or mental state in which they are found. Secondly, neutrality requires that those 
who are involved in relief operations will not influence the outcome of a conflict or interfere with political tensions through their actions. Lastly, impartiality implies that no group of people will be favoured above another.

Humanitarian logistics closely resembles that of commercial supply chain management, except that the objective of maximising profit is now replaced by the objective to balance speed and cost. Great insights have been gained in humanitarian logistics by comparing it to its commercial counterpart; however, much still needs to be done to instil the principles of commercial supply chain management in the humanitarian logistics environment. The basic principles and characteristics of humanitarian logistics are elaborated on in, inter alia, Beamon (2004:1), Maspero and Ittmann (2008:178), Oloruntoba (2009:198, 201-202) and Tomasini and Van Wassenhove (2009a:550-51). Tomasini and Van Wassenhove (2009b) also find it necessary to emphasise the importance for those wanting to offer humanitarian aid to understand the humanitarian space.

However, human suffering in South Africa extends far beyond the events that can strictly be classified as 'disasters'. Many complex societal issues such as poverty, lack of education and crime contribute greatly to the daily anguish of millions of South Africans. It is, therefore, our opinion that any form of logistics that aims to relieve such suffering also falls under the banner of humanitarian logistics. This broadens the spectrum of humanitarian logistics significantly as operations of Non-Governmental Organisations (NGOs) and Non-Profit Organisations (NPOs) that provide material support to impoverished people on a daily basis or services such as breastmilk banking and home-based care suddenly also form part of humanitarian logistics.

The South African humanitarian logistics context can now be expanded from merely considering conventional disasters in South Africa to a field that includes the operations of various NGOs and NPOs that attempt to relieve any form of human suffering caused by 'disastrous events' not normally classified as disasters.

\section{Disaster management and humanitarian logistics opportunities in South Africa}

The context of South African disaster management and humanitarian logistics, as discussed in this paper, holds many opportunities for collaborative research within the fields of humanitarian logistics. The greatest opportunity probably lies in translating models, theories and best practices from the commercial world and the international humanitarian community into practicable solutions for the South African context. For example, the following research questions could be asked:

- How can the best practices of public-private partnerships with the likes of Wal-Mart and UPS (in the USA) be applied within the South African socio-economic climate to leverage better co-operation during disaster response? 
- How can epidemiology models inform the pre-positioning and distribution of vaccines and medical supplies in the event of an outbreak?

- How can the cutting edge disaster response processes of humanitarian giants such as the World Health Organisation (WHO), Red Cross and Doctors Without Borders (MSF) be mimicked by smaller-scale South African role-players?

- What insights can be gained from disaster response successes and failures in other African countries?

- How can the operations of NGOs or NPOs dealing with 'non-traditional disasters' such as poverty and a lack of education be improved and sustainable solutions implemented?

This is a very limited list of questions to illustrate how broad the field of humanitarian logistics is and how many research gaps there are within the South African context. The following section presents an overview of two recent South African case studies where the last research question on the list presented above, is addressed.

\section{SOUTH AFRICAN CASE STUDIES}

Two recent South African case studies are identified and discussed in this section. The first is a case study at Heartbeat by Du Plessis, Bean, Schoeman and Botha (2011) and the second a case study at the South African Breastmilk Reserve (SABR) by Bean, Viljoen, Modise, Cooper and Schoeman (2010). Both case studies focused on developing sustainable solutions to help NPOs to improve their operations and ability to deal with non-traditional disasters.

\section{Heartbeat}

Even though HIV/Aids is one of the major causes of deaths in South Africa, the consequences of HIV/Aids extends far beyond the death of infected individuals. According to UNICEF (2009:8), the high prevalence of HIV/Aids in South Africa has resulted in high rates of orphaned children and currently it is estimated that around 3.7 million children in South Africa have lost one or both parents.

Heartbeat is an NPO as well as a Section 21 company in South Africa that was founded in 2001 by a group of unpaid volunteers. The organisation exists to alleviate the suffering of Orphaned and Vulnerable Children (OVC) by facilitating change in communities. Heartbeat works with the OVC in communities, mobilising circles of support around the children instead of removing children from their houses or communities of origin. Heartbeat also provides food, clothes and other necessary items to the OVC and thereby relieves the suffering of many children in South Africa.

\section{Problem description}

Heartbeat tries to provide stability, care and protection to OVC by assuming the role of a parent or caregiver. This is achieved through regular home visits to OVC families. The home 
visits are performed by trained homecare workers who assess the current state and situation of OVC households; provide counselling, assistance with homework and household chores; mediate in the case of disputes; and address problems in the household. To build trusting relationships with and provide stability to OVC, it is critical for each homecare worker to be assigned to specific OVC households to ensure that the same homecare worker visits a household every time (Du Plessis et al., 2011).

According to Du Plessis et al. (2011), Heartbeat has determined that a ratio of one homecare worker for every ten households is ideal for providing regular high quality visits; however this ratio is exceeded by far due to limited staff. This impairs the ability of homecare workers to provide high quality support and services to OVC. This, combined with the fact that there is no structured approach to assigning household visits to homecare workers, results in visits being performed on an ad hoc and unstructured basis. This often leads to some OVC households not being visited as often as required or OVC not being home when a home visit is conducted.

\section{Solution approach}

In a recent study performed by Du Plessis et al. (2011), the abovementioned problems are addressed by developing a solution algorithm that assigns, routes and schedules homecare worker visits to ensure that homecare workers have similar workloads and that all the OVC households can be visited the required number of times per week. This solution algorithm uses a combination of Variable Neighbourhood Search (VNS) and Tabu Search (TS) to route homecare workers while reducing the travel time of homecare workers, satisfying OVC and Heartbeat requirements and balancing the workload between all available homecare workers.

VNS is a metaheuristic that explores different neighbourhoods of a current solution and jumps from the current solution to a new one when an improvement can be made (Hansen \& Mladenović, 2001:450). The VNS algorithm is applied repeatedly to get a local optimal solution from the various neighbouring solutions. TS is a method that uses the properties of human memory to prevent future mistakes based on mistakes of the past by adding prohibited moves to a tabu list (Winston \& Venkataramanan, 2003:815). The TS metaheuristic has the ability to avoid local optimal solutions, as it allows non-improving moves in order to allow the algorithm to get to the global optimal solution.

The VNS and TS metaheuristics are combined by Du Plessis et al. (2011) by first using VNS to find improved homecare worker schedules by swapping activities of different care workers and then using TS to evaluate the quality of the proposed swap. When no more schedule improvements can be made, the algorithm is terminated and a second VNS initiated. This search is done for every individual homecare worker and swaps different activities in each 
care worker's schedule to find improved solutions. The quality of these solutions is again evaluated using TS.

The algorithm was then applied to the Nellmapius project site to evaluate the validity and usability of the algorithm. The chosen project site was at Nellmapius, a settlement east of Pretoria with an estimated population of 65 000, where Heartbeat serves 132 OVC households at the project site with five homecare workers. After performing various data-gathering and pre-processing activities, Du Plessis et al. (2011) were able to obtain a solution for this application.

\section{Results and findings}

Du Plessis et al. (2011) state that the newly developed homecare worker schedules address many of Heartbeat's problems. Their solution approach enables work to be fairly distributed between homecare workers, enables the effective routing and scheduling of homecare workers that allows them to conduct all their visits after school, and results in limited homecare worker variation by permanently allocating a specific homecare worker to a household.

\section{The South African Breastmilk Reserve (SABR)}

Due to the prevalence of HIV/Aids in South Africa, many mothers of premature infants are unable to lactate as a result of poor maternal health. In addition, the high rate of poverty in South Africa often hampers mothers' attempts to visit their premature infants in hospitals, and consequently the opportunity to breastfeed their children diminishes. This leaves many premature infants vulnerable, as healthy breastmilk drastically reduces an infant's risk of contracting necrotising enterocolitis, a fatal inflammation of the intestines, and other similar diseases (South African Breastmilk Reserve, 2007).

The SABR is a public benefit organisation that alleviates the suffering of premature infants throughout South Africa by sourcing, pasteurising and redistributing donor breastmilk to vulnerable babies. The SABR runs according to a franchising model whereby they supply the equipment, supplies and the operating model necessary to establish in-hospital milk banks. The hospitals are then responsible for the operation of the milk bank. The SABR maintains strict control over the milk banks to ensure that donor breastmilk is distributed in an equitable way and that health and safety regulations are adhered to.

\section{Problem description}

Due to the recent rapid expansion rate, the SABR needs to cope with constant pressures on its network. The growth in demand led to a lack of human and financial resources available to successfully perform operations, as well as a diverse set of unstructured operating procedures which in turn inhibit sustainable future growth of the SABR network (Bean et al., 2010:3). 
To help the SABR develop a sustainable expansion plan, Bean et al. (2010:3) comment that operating procedures had to be simplified, standardised and streamlined to ensure that everyone in the network knows what must be done and when.

\section{Solution approach}

To assist the SABR to realise its expansion goal of building a sustainable breastmilk banking infrastructure throughout South Africa, Bean et al. (2010:4) developed a simplified operational model that rid the SABR of functional processes to allow it to focus on its core function of support, co-ordination, monitoring and planning. This simplified operational model allows for the SABR network to be decentralised while spreading the workload between different network role-players and reducing the operational load on the SABR staff.

In addition to the simplified operational model, Bean et al. (2010:5) also developed a mathematical model that focuses on a geographical area and determines the number of SABR corners - a decentralised delivery and collection point for materials and donor breastmilk (Bean et al., 2010:2) - to be established in the most appropriate locations for them. This model was then applied to the Gauteng province in South Africa to determine where new corners should ideally be established in that province (Bean et al., 2010:6). Various data-collection and pre-processing activities were performed before the actual solution could be obtained. The interested reader is referred to Bean et al. (2010:6-8) for additional information on these activities.

\section{Results and findings}

When a solution for the mathematical model could be obtained, a sensitivity analysis was performed which indicated that the total donor benefit increases at a decreasing rate as the number of corners increases (Bean et al., 2010:8). At some point in the sensitivity analysis, a point is reached where no additional benefit is achieved, which indicates that at some point the cost of placing an additional corner does not justify the cost of the additional corner.

In concluding their paper, Bean et al. (2010:10) highlight that the aim of the work undertaken was to aid the SABR in their mission to decrease South Africa's infant mortality by providing them with safe and pasteurised breastmilk. This was achieved by simplifying the SABR operational model, improving its network design, and developing a mathematical model to assist with the planning of the SABR network structure by determining the number of additional corners to be established and appropriate locations for these corners.

\section{CONCLUSION}

South Africa is not internationally recognised as a country affected by large-scale disasters and consequently the need for disaster management in South Africa is often neglected. However, even though the smaller-scale disasters occurring in South Africa may be regarded 
as minor, the reality is that the impact of a seemingly negligible disaster can be exacerbated significantly due to the living conditions and subsequent vulnerability of people living in informal settlements. This emphasises the need to focus on disaster management in South Africa, with particular emphasis on disaster-vulnerable areas such as informal settlements.

Currently there are various stakeholders involved in disaster management initiatives for South Africa. Even though the key stakeholders in South African disaster management are similar to the rest of the world, South African society has unique characteristics that directly influence disaster management activities. Sensitivity, community awareness and cultural differences may significantly complicate disaster relief efforts in South Africa, and many other African countries, and should be important considerations during disaster management.

Humanitarian logistics is a primary constituent of disaster management and resembles that of commercial supply chain management, except that the objective to balance speed and cost is usually considered, as opposed to maximising profit. However, the field of humanitarian logistics can be broadened to extend far beyond events that can be classified strictly as 'disasters' and any form of logistics that aims to relieve human suffering also falls under the banner of humanitarian logistics.

Until recently the field of humanitarian logistics did not receive the necessary attention in practical and academic circles, but this trend is changing. Various disciplines are drawn towards humanitarian logistics and are finding ways to contribute to the field. Many researchers, especially in the developed world, are seeking opportunities for collaboration in humanitarian logistics. This holds a great opportunity for all South African, and African, roleplayers in humanitarian logistics. Case studies show the impact and value of humanitarian logistics, but it is a field that requires much more attention. 


\section{REFERENCES}

Altay, N. \& Green, W.G. III. 2006. OR/MS research in disaster operations management. European Journal of Operational Research, 175:475-93.

Beamon, B.M. 2004. Humanitarian relief chains: Issues and challenges. Conference proceedings of the 34th International Conference on Computers and Industrial Engineering held in San Francisco, USA. November 14-16.

Bean, W., Viljoen, N., Modise, M., Cooper, A. \& Schoeman, C. 2010. Strategic Decision Support for the Expansion Strategy of a National Breastmilk Banking Network. Proceedings of the 3rd Biennial CSIR Conference: Science Real and Relevant. Pretoria, South Africa. August 30-September 1.

Du Plessis, W., Bean, W., Schoeman, C. \& Botha, J. 2011. Home and Community-based Care in South Africa. OR/MS Today, 38(2).

Georgia Institute of Technology. 2010. Plenary sessions and informal discussions. The 2010 Health and Humanitarian Logistics Conference. Center for Humanitarian Logistics held at the Georgia Institute of Technology, Atlanta, USA. March 4-5.

Hansen, P. \& Mladenović, N. 2001. Variable neighbourhood search: Principles and applications. European Journal of Operational Research, 130: 449-67.

Kovàcs, G. \& Spens, K.M. 2007. Humanitarian logistics in disaster relief operations. International Journal of Physical Distribution \& Logistics Management, 37(2):99-114.

Maspero, E.L. \& Ittmann, H.W. 2008. The rise of humanitarian logistics. Paper presented to the 27th Annual Southern African Transport Conference held in South Africa.

National Disaster Management Centre. 2008. Annual Report 2007/2008. Available from http://www.ndmc.gov.za/Documents/AnnualReports/tabid/256/ct//ViewDocum ent/ mid/625/ItemID/149/Default.aspx (Accessed 14 July 2010).

Oloruntoba, R. 2009. On Relief and Supply Chain Similarities. Conference proceedings of the 14th Annual Logistics Research Network Conference held at Cardiff. September 9-11.

Perry, R.W. \& Lindell, M.K. 2003. Preparedness for emergency response: Guidelines for the emergency planning process. Disasters. 27(4):336-50. 
Republic of South Africa. 2003. Disaster Management Act, Act 57 of 2002. Government Gazette. Vol. 451.

South African Breastmilk Reserve. 2007. The Feed for Life Initiative: In-service Training Manual.

South African Red Cross Society. 2006. Five Year Strategic Development Plan 2006-2010. Available at http://www.redcross.org.za/Portals/1/5-YSDP101206_final.pdf (Accessed 14 July 2010).

Thomas, A.S. \& Kopczak, L.R. 2005. From Logistics to Supply Chain Management: The path forward in the humanitarian sector. The Fritz Institute. Available from: http://www. fritzinstitute.org/PDFs/WhitePaper/FromLogisticsto.pdf (Accessed 14 July 2010).

Tomasini, R. \& Van Wassenhove, L.N. 2009a. From preparedness to partnerships: case study research on humanitarian logistics. International Transactions in Operations Research, 16:549-59.

— 2009b. Humanitarian Logistics. London, UK: Palgrave.

UNICEF South Africa. 2009. Annual Report. Available from: http://www.unicef.org / southafrica/SAF_resources_annual2009.pdf (Accessed 30 July 2010).

Van Wassenhove, L.N. 2006. Humanitarian aid logistics: supply chain management in high gear, Journal of the Operational Research Society, 57:475-89.

Viljoen, N.M. 2010. Developing a South African paradigm of humanitarian logistics. 6th Annual State of Logistics survey for South Africa. CSIR. Pretoria. RSA.

Winston, W.L. \& Venkataramanan, M. 2003. Introduction to Mathematical Programming, Operations Research: Volume One. Thomson Brooks/Cole. 


\section{List of abbreviations}

\begin{tabular}{|l|l|}
\hline CBO & Community-Based Organisation \\
\hline DM & Disaster Management \\
\hline DME & Department of Minerals and Energy \\
\hline DMISA & Disaster Management Institute of South Africa \\
\hline DoA & Department of Agriculture \\
\hline DoSD & Department of Social Development \\
\hline DST & Department of Science and Technology \\
\hline DWAF & Department of Water Affairs and Forestry \\
\hline FBO & Faith Based Organisations \\
\hline MSF & Doctors Without Borders \\
\hline NDMC & National Disaster Management Centre \\
\hline NGO & Non-Governmental Organisation \\
\hline OVC & Orphaned and Vulnerable Children \\
\hline NPO & Non-Profit Organisation \\
\hline SABR & South African Breastmilk Reserve \\
\hline SAPS & South African Police Service \\
\hline TS & Tabu Search \\
\hline UNICEF & United Nations Children's Fund \\
\hline VNS & Variable Neighbourhood Search \\
\hline WHO & World Health Organisation \\
\hline
\end{tabular}

